\title{
ENTORN DE LA DISCRIMINACIÓ SEXISTA A L'ESCOLA
}

\author{
Marina Subirats
}

Després d'analitzar les xifres corresponents a inscripcions d'alumnes (homes $\mathrm{i}$ dones) d'universitats $\mathrm{i}$ centres escolars als Estats Units $\mathrm{i}$ a Espanya, l'article tracta de demostrar que l'escola no es comporta d'una manera neutra respecte als sexes, especialment pel que fa a titulacions socialment prestigioses i a la consecució de treball professional.

Analitzem també els models educatius per a plantejar finalment les complexitats i les dificultats d'un canvi cultural que determini la desaparició dels diferents rols socials, segons el sexe. 
En aquest curs 1977-1978, i per primera vegada a la història, hi ha més dones que homes estudiant a les universitats nord-americanes. Un fet, entre d'altres, que marca l'amplitud de la presència que la dona ha aconseguit en l'ensenyament, fins $i$ tot en l'ensenyament superior. Aparentment, la igualtat educativa s'ha acomplert, almenys en alguns països.

Les xifres, però, no són suficients per a convèncer-nos que les oportunitats de les dones, en el camp de la cultura, són ja iguals a les dels homes. L'experiència personal de cada dona li permet de comprovar el manteniment d'unes diferències, encara que, sovint, no pugui explicar exactament en què consisteixen. I si mirem les posicions ocupades per les dones en els llocs de treball, aquesta experiència es confirma: el creixement educatiu femení no ha anat acompanyat d'un creixement parallel en l'accés als treballs més ben pagats i més prestigiosos. Deixarem de banda, però, en aquestes notes, l'anàlisi del mercat de treball, en el qual intervenen factors diferents als pròpiament educativ.s. Ens centrarem fonamentalment en l'escola - tenint en compte, però, que actualment no és tampoc l'únic aparell educatiu- i en una qüestió molt concreta: hi ha o no igualtat d'oportunitats per a homes i dones a través de l'aparell escolar? Es pot parlar, encara, de discriminació sexista? Tendeixen a desaparèixer les desigualtats de nivell cultural entre els sexes, o es mantenen encara? I si és així, per quins mecanismes, en uns sistemes escolars que, d'una manera general, es presenten com a igualitaris?

\section{El manteniment de les distàncies culturals}

Hi va haver un temps en què la discriminació cultural de la dona passava per un mecanisme evident: el menor nombre d'anys dedicats a l'educació, en relació a l'home, dins de cada classe social. Fenomen no totalment eliminat: encara, a Espanya, el nombre de dones analfabetes és superior al d'homes, especialment en les edats més avançades. 
En el conjunt de les societats occidentals, però, aquest fenomen ja no és la causa principal del menor grau cultural de les dones. En alguns casos ens trobem fins $i$ tot en una situació inversa: les dones passen, com a mitjana, més temps dins els aparells escolars que els homes.

Ara bé, que el nombre d'anys passats a l'escola sigui, actualment, similar per als dos sexes no té com a conseqüència que les titulacions $i$ els nivells acadèmics assolits siguin també similars. $\mathrm{Si}$ afirmem que continua mantenint-se una discriminació de sexes dins l'aparell educatiu no és per un convenciment a priori, sinó perquè existeixen uns indicadors concrets que ho demostren. Que, a mateix nombre d'anys dedicats a estudiar, les dones aconsegueixen resultats inferiors demostra que alguna cosa passa, que alguna trava suplementària troben, trava que no és avui evident $i$ que cal comprendre i explicar. A no ser, és clar, que creguem que la intelligència està repartida de forma desigual entre els sexes, creença que fa inútil tota anàlisi de l'aparell escolar. Com que aquest no és el nostre cas, les diferències les hem de buscar no en els individus, sinó en l'aparell a través del qual obtenen les qualificacions.

Observant els tipus de nivells i els títols obtinguts pels individus dels dos sexes, dues diferències són notòries:

1. El nivell de titulació de les dones és sempre més baix que el dels homes, $i$, malgrat l'aparença que aquestes diferències tendeixen a disminuir, no és així, sinó que es mantenen. Vegeu el quadre I, que ens dóna l'evolució educativa, per sexes, als Estats Units.

\section{QUADRE I}

\begin{tabular}{|c|c|c|c|c|c|c|}
\hline & \multicolumn{2}{|c|}{ Batxillerat } & \multicolumn{2}{|c|}{ Llicenciats } & \multicolumn{2}{|c|}{ Doctors } \\
\hline & Homes & Dones & Homes & Dones & Homes & Dones \\
\hline 1930 & $54,3 \%$ & $45,7 \%$ & $79,4 \%$ & $20,6 \%$ & $84,9 \%$ & $15,1 \%$ \\
\hline 1950 & 74,7 & 25,3 & 78,8 & 21,2 & 90,3 & 9,7 \\
\hline 1970 & 56,8 & 43,2 & 65,0 & 35,0 & 86,7 & 13,3 \\
\hline
\end{tabular}

Font: D. L. Adkins, The Great American Degree Machine.

1. D. L. Adkins, The Great American Degree Machine, The Carnegie Comission on Higher Education, 1975. 
En xifres absolutes, el creixement de les titulades, a tots els nivells, ha estat espectacular; però, en percentatges, els guanys de les americanes en el terreny de la cultura són gairebé inexistents, en un període de quaranta anys, i malgrat que el temps passat a les institucions educatives és lleugerament superior, com a mitjana, al dels homes. En els graus de batxillerat i doctorat, el percentatge de dones que els aconsegueixen, en relació al total dels individus que els obtenen, és lleugerament inferior l'any 1970 del que era l'any 1930. En l'únic nivell en què s'experimenta un augment important és en el de la llicència, fet que cal posar directament en relació amb l'exigència actual del grau de llicència per a una sèrie d'especialitats considerades femenines.

En el cas espanyol, la fragmentació de les dades estadístiques no permet de fer el mateix tipus de comparació a través del temps. És possible, però, que els nivells educatius femenins hagin crescut, sobretot des del 1960, més que els masculins, fent aparèixer una tendència a la igualació de nivells. Però aquest fenomen es deuria al fet que partim d'una baixíssima escolarització femenina en l'ensenyament mitjà i superior, i no permet de concloure que les diferències aniran disminuint indefinidament, sobretot si tenim en compte l'evolució en altres països, com en el cas més amunt indicat. De fet, les diferències de nivell educatiu segons els sexes són de les més altes d'Europa: el percentatge de dones en l'ensenyament secundari, l'any 1970, és el més baix, comparat a altres països europeus. Vegem la magnitud d'aquestes diferències de nivell educatiu entre els sexes, en el quadre II.

\section{QuADRE II}

Percentatge de població de 15 anys o més

que no està estudiant actualment, per

sexe i nivell d'ensenyament iniciat $o$ acabat.

\begin{tabular}{|c|c|c|}
\hline & Homes & Dones \\
\hline Pre-escolar i primària & 48,4 & 51,6 \\
\hline Segon grau - primer cicle ... & 54,2 & 45,8 \\
\hline Segon grau - segon cicle .................. & 60,6 & 39,4 \\
\hline Tercer grau no universitari .............. & 52,7 & 47,3 \\
\hline Tercer grau universitari o equivalent ... & 84,8 & 15,2 \\
\hline
\end{tabular}

Font: INE, cens del 1970. 
El menor nivell educatiu aconseguit per les dones es fa evident des del batxillerat elemental - segon grau - primer cicle - i és acusadíssim en l'accés a la Universitat, on, d'altra banda, l'abandó dels estudis és més freqüent entre les dones que entre els homes $(11,9 \%$ i $7,5 \%)$, a diferència d'altres cicles, on les dones acaben més sovint els estudis començats. En el cas dels estudis no universitaris, l'alta proporció de dones es deu a la inclusió en aquest apartat d'alguns estudis mitjans d'alta proporció femenina, en els quals, per tant, hi ha menys competència per adquirir la titulació.

2. A igualtat de nivell de titulació, les dones es troben en les especialitats menys valorades socialment, $i$ són gairebé excloses de les més valorades. I, si analitzem l'evolució, podem comprovar que la distinció entre carreres masculines i carreres femenines -és a dir, carreres en què els homes o les dones són predominants, sense que això pressuposi, per part nostra, cap valoració d'una major adequació dels estudis a un dels sexes- no tendeix a desaparèixer, sinó que es manté.

El fenomen és prou conegut com perquè calgui recórrer a demostracions empíriques. Per a recordar-ne la magnitud, únicament, vegeu la distribució de les estudiantes en la Universitat espanyola, durant el curs 19711972.

\section{QUADRE III}

\section{Facultats}

Ciències

Ciències Polítiques i Econòmiques ...

Dret

Farmàcia

Nombre d'alumnes

$\%$ de dones

Filosofia i Lletres ....................

Medicina

43.196

25.817

24.824

8.353

52.190

38.308

2.166

194.854
15,7

30,3

55,1

55,4

22,9

17,1

Total 35,9 


\section{Escoles Tècniques Superiors Nombre d'alumnes \% dedones}

\begin{tabular}{|c|c|c|}
\hline Arquitectura $\ldots . . . . . \ldots \ldots \ldots$ & 10.156 & 9,0 \\
\hline Aeronàutica ................... & 1.625 & 0,7 \\
\hline Agrònoms $\ldots . . . \ldots \ldots \ldots \ldots$ & 2.779 & 4,6 \\
\hline Camins $\ldots \ldots \ldots \ldots \ldots \ldots \ldots$ & 3.982 & 0,6 \\
\hline Industrials $\ldots \ldots \ldots \ldots \ldots \ldots$ & 13.999 & 0,7 \\
\hline Mines $\ldots . . . \ldots \ldots \ldots \ldots \ldots \ldots$ & 1.298 & 0,8 \\
\hline Monts ........................ & 636 & 3,9 \\
\hline Navals ....................... & 1.210 & 0,4 \\
\hline Telecomunicacions ............ & 3.621 & 2,5 \\
\hline Politècnic (València) ......... & 1.427 & 4,1 \\
\hline Escoles no estatals .......... & 2.245 & 5,0 \\
\hline Totals ......... & 42.978 & 3,2 \\
\hline
\end{tabular}

Font: INE, Estadistica de la enseñanza en España, 1970.

En les carreres tècniques, les estudiantes -quantes acabaran els estudis, i quantes exerciran?- són encara només el 3,2 \%, l'any 1972, mentre continuen concentrant-se, en canvi, en estudis com lletres o farmàcia. I dins de les facultats, hi ha especialitats típicament «femenines». Fenomen, encara, característic, no del nostre país, sinó del món occidental, en el seu conjunt. Diu, per exemple, Juliet Mitchell, referint-se a Anglaterra: «En principi, no hi ha diferència entre nois $i$ noies en el tipus de disciplines acadèmiques que estudien a l'ensenyament mitjà. En la pràctica, hi ha una ominosa diferència, que podem comprovar en els temes d'exàmens. Les noies escullen ciències en una proporció de menys de dos terços que els nois, i matemàtiques, en menys de la meitat. La ciència que les noies escullen és biologia, més que no pas física o química, cosa que aparentment indica una preferència (quina?) per l'humà $i$ tangible, com a oposat a l'abstracte i teòric. A la Universitat, només un $2 \%$ d'aquestes poques dones en les facultats de ciències triaran ciències aplicades, més de la meitat, biologia. A tot arreu les dones són dissuadides de ser científiques.» ${ }^{2}$

2. J. Mitchell, Women's Estate, Doubleday, Nova York, 1973, p. 132. 
En el cas dels Estats Units, una detallada anàlisi estadística -que no reproduïm aquí per la seva llargada - permet a Radner i Miller ${ }^{3}$ d'establir que, no solament no hi ha hagut, en quaranta anys, igualació de les especialitats entre els sexes, en l'educació, sinó que sembla existir una tendència contrària: les dones tendeixen a perdre preponderància en les especialitats en què tenien alta participació, quan aquestes especialitats tenen un cert prestigi, com per exemple en els departaments universitaris d'història i literatura. La participació femenina baixa en aquests departaments, en relació a la masculina; mentre que, en canvi, les especialitats d'alta proporció masculina continuen gairebé tancades a la dona. És a dir, hi ha una certa tendència a la masculinització dels camps més prestigiosos on s'havia aconseguit una alta participació femenina, sense que les dones guanyin posicions en altres tipus d'estudis.

És a dir, l'escola no es comporta de manera neutra en relació als sexes. $O$, dit d'una altra manera, cada sexe té, en el conjunt de l'aparell escolar, unes oportunitats diferents d'adquisició de cultura. L'explicació psicologista ho atribuirà a diferències de comportament entre els sexes: les dones estudien menys, o són menys intelligents, i per això no arriben al mateix nivell de titulacions. I, quant a les especialitats, són elles qui lliurement les trien. Enfront d'aquest tipus d'explicació, nosaltres fem la hipòtesi que és el propi aparell escolar el que introdueix una diferència de tractament segons el sexe - com també, evidentment, segons altres criteris, més estudiats ja: la classe social, el grup ètnic, el grup cultural, etcètera-, és a dir, el que, a través d'unes pautes específiques, provoca un èxit diferent en els estudis, entenent per èxit el criteri habitual: aconseguir titulacions prestigioses.

\section{Els models educatius segons els sexes: escola separada $i$ escola mixta}

Els patrons d'educació masculins i femenins varien, d'acord amb la concepció que cada societat té del paper de cada sexe. Si ens referim al sistema d'educació a través de l'escola - que com a forma de socialització generalitzada és una invenció molt recent- podem distingir dos models diferents en el tractament que es dóna a la diferència de sexes a l'interior del sistema escolar: l'escola que manté la separació de sexes i l'escola mixta.

3. R. Radnet i L. S. Miller, Demand and Supply in US Higber Education, Carnegie Commission on Higher Education, 1975. 
En el primer cas, s'afirma la necessitat de mantenir una separació entre escoles masculines $i$ escoles femenines, perquè, al mateix temps, es posa l'èmfasi en la diferència de rols socials de cada sexe. Les raons últimes que es donen per a justificar els diversos rols socials són, però, les d'un determinisme biològic: la naturalesa ha creat l'home i la dona per a funcions diferents, i l'educació és el procés a través del qual cada un d'ells ha d'arribar a assumir plenament les capacitats per a realitzar aquestes funcions. ${ }^{4}$

Teòricament, la separació escolar no té perquè comportar desavantatges per a la dona, ja que la ideologia que suporta aquesta separació li atribueix un paper social específic, els valors típics del qual són generalment exalçats. En la pràctica, els desavantatges són evidents: en la mesura que el que realment es valora són les activitats masculines, el món d'activitats reservades a la dona té un caràcter marginal. En conseqüència, l'educació considerada pròpia de la dona és extremadament pobra: no la prepara ni per funcions específiques ni per a funcions generals de la societat. En efecte, quins han estat els trets específics de l'educació «femenina»? La «costura» ha estat potser el més generalitzat, però ni en aquest camp l'escola donava una vertadera competència a la nena. Les «nocions» de cuina, puericultura, etcètera, no han tingut mai cap mena de seriositat, han estat el contrari d'un aprenentatge: la banalització d'unes tasques, repetides sense interès ni ganes. ${ }^{5}$ Fins $i$ tot en els casos dels models d'educació de les nenes de classe alta, que comporten, generalment, l'adquisició de coneixements més complexos — piano, francès, formes de comportament, etcètera- l'ensenyament es $\mathrm{fa}$ de tal manera que la noia comprèn que seria impropi prendre'l seriosament. l's a dir, més que formes de cultura específiques, el que comporta el model d'ensenyament femení és una degradació del que aprendran els nens, més algunes pràctiques rutinàries lligades al paper de la dona dins la família.

L'afirmació de la diferència entre els sexes, com a base d'una educació diferent i clarament discriminatòria, no podia, però, mantenir-se indefinidament: la ideologia pròpia de les societats occidentals reposa, en l'actual etapa històrica, en l'afirmació de la igualtat formal dels individus: davant

4. Punts de vista gairebé exclusius a Espanya, durant els segles xIx i xx, fins $i$ tot en els sectors liberals. (Vegeu, per exemple, G. di Febo, Orígenes del debate feminista en España, dins «Sistema», núm. 12, gener 1976.) I que en els primers anys del franquisme s'emfatitzen com una de les bases del sistema escolar.

5. Els llibres d'Escuela-Hogar, editats per la Secció Femenina durant els anys cinquanta, constitueixen un dels exemples més perfectes d'aquesta banalitat i d'aquesta superficialitat volgudes en un ensenyament: situació, en si mateixa, paradoxal i contrària a totes les altres normes escolars. 
la llei, tots tenen uns mateixos drets. D'aquí ve que l'escola separada hagi pogut ser atacada, i que, lentament, vagi desapareixent. Molt lentament, però. Perquè cal no oblidar que la igualtat formal dels sexes ha estat més difícil d'imposar que la igualtat formal dels membres de les distintes classes socials. Recordem, per exemple, que la implantació del sufragi universal masculí precedeix, de molts anys, la consecució del vot femení. És a dir, si bé en l'estructura ideològica capitalista hi ha elements que tendeixen a afavorir la igualtat formal dels individus, la desigualtat sexista és generalment un element més persistent que la desigualtat classista, en el terreny de la legislació i els drets formals. Així, per exemple, el franquisme no teoritza la desigualtat escolar de les classes socials, encara que, en la realitat, crei xarxes d'escoles totalment diferenciades segons la classe social. Afirmar que l'escola dels pobres havia de ser diferent a la dels rics hauria estat inadmissible, fins $i$ tot en la societat dels anys quaranta. El escassos textos en què s'estableix una diferència - per exemple, en la legislació del 1938 sobre l'ensenyament mitjà - eviten la definició en termes de grups socials. En canvi, la diferència sexista és totalment emfatitzada, a partir de raons «naturals» que ningú no gosa ja aplicar a les diferències de classe.

D'aquí que, malgrat que l'escola mixta guanyi terreny, continuï mantenint-se, encara, escoles d'un sol sexe, i no solament a Espanya. A Anglaterra, per exemple, més d'un terç de les escoles són d'un sol sexe, en entrar a la dècada dels setanta. ${ }^{6}$

El naixement d'un model escolar mixt ha estat difícil, $i$, fins a cert punt, contradictori. Pierrette Pezerat ${ }^{7}$ ha analitzat alguns dels escrits de dones que van propugnar la seva aparició: textos carregats de tota l'ambigüitat de tantes lluites femenines. La demanda d'un major grau d'escolarització per a les nenes, d'un tracte igualitari a l'escola, no es justifica per la necessitat de donar-los un mateix grau de cultura que als nens, sinó perquè es considera que així seran capaces de donar una millor educació als fills i d'ajudar més eficaçment el marit. Per a les assagistes que, a finals del XVIII i començaments del xIx, propugnen a França la coeducació, la dona és encara inferior a l'home, $\mathrm{i}$ tot la destina a unes tasques específiques, lligades a la família. ¿Es tracta, potser, d'una maniobra tàctica, destinada a millorar l'ensenyament femení sense esverar la societat benpensant? És possible, però res en aquests escrits no ho indica clarament. $\mathrm{La}$ influència benèfica de les nenes damunt el comportament dels nens, en l'educació mixta, és encarạ un altre argument esgrimit. És a dir, no hi ha

6. J. Mitchel, op. cit., 1973, p. 131.

7. P. Pezerat, La vertue necessaire i Petites filles en éducation, dins «Les Temps Modernes», núm. 358, maig 1976. 
una reivindicació d'una cultura igual, com a dret de la dona, sinó que posen l'accent en els avantatges que la societat masculina pot obtenir si la dona adquireix un major grau de cultura.

Posteriorment, apareixen altres tendències. En els corrents progressistes de la pedagogia s'inclou la coeducació, entesa, generalment, com a neutralitat sexual. Més que parlar del nen i la nena, es parla de l'infant: les connotacions sexuals desapareixen, perquè hi ha, al mateix temps, la negació d'una sexualitat infantil específica. És encara el model més favorable per a la dona, en termes d'igualtat educativa. En efecte, l'única alternativa és la conservadora que, o manté escoles separades, o introdueix assignatures especials, sempre sobre la base que les dones no necessiten ni tenen interès a rebre el mateix tipus d'educació que els homes. L'escola mixta, especialment sí, a més, intenta realitzar la coeducació, és, per tant, l'escola de la igualtat formal: nens $i$ nenes bi són educats com a individus teòricament iguals. Fins $i$ tot quan es mantenen assignatures o pràctiques específiques, aquestes tenen un pes molt secundari: les assignatures principals són comunes als dos sexes, $i$, per tant, desapareixen les diferències formals entre educació femenina i masculina. Però si insistim en el terme «formals» és perquè, segons hem vist prèviament, els resultats continuen essent diferents, $\mathrm{i}$, per tant, aquest fet indica que algun tipus de diferència es manté encara, més difícil de precisar perquè no és visible en l'estructura escolar.

\section{Cultura masculina}

El model d'educació de l'escola mixta no ha estat el resultat de la fusió de dos models anteriors, el masculí i el femení, sinó la generalització d'un d'ells, el que anteriorment es considerava masculí.

I és que, de fet, el model femení, com hem dit anteriorment, tenia ben poc d'específic, i eta, sobretot, la degradació de l'ensenyament masculí. La legislació espanyola del segle XIx, que retalla les assignatures de les nenes, ho explica ben clarament. La tasca de contraposar a la cultura actual una cultura femenina reprimida és ben difícil, i recorda les famoses polèmiques sobre la ciència proletària. Si per cultura entenem els coneixements sistematitzats sobre la realitat, seguint el model de les ciències, cal dir immediatament que no hi ha una cultura específicament femenina, sinó una cultura de la humanitat, en la construcció de la qual, d'altra banda, les dones han participat ben poc.

Però hi ha altres aspectes de la cultura, que també transmet l'escola, i que no es refereixen al coneixement de la realitat, sinó que serveixen per 
orientar els comportaments: els sistemes de valors. Sistemes de valors que, en si mateixos, no són específics de cap grup humà, però que sovint els són socialment atribuïts.

En aquest sentit, hi ha un sistema de valors històricament masculins, i un sistema de valors històricament femenins, sistemes que han estat utilitzats per a configurar la diferència de papers socials, $i$, en definitiva, per assegurar el paper subordinat de la dona.

El caràcter «masculí» de la cultura que transmet avui l'escola no es deu al fet que s'hi ensenyi història o matemàtiques, disciplines desenvolupades fonamentalment per homes; es deu al fet que els valors $i$ els comportaments masculins són considerats superiors. I no d'una manera abstracta, sinó molt concreta: els comportaments i els valors dels nens reben generalment una aprovació molt més clara que els de la nena, siguin quins siguin, i com a conseqüència de la posició predominant dels homes dins la nostra societat.

Aquest fenomen és tan generalitzat que el trobem fins $i$ tot en els llocs més impensats. Així, per exemple, en el llibre - d'altra banda excellent- d'E. G. Belloti, llibre que emprèn l'anàlisi de les discriminacions a l'escola segons els sexes. A l'hora d'explicar el punt de vista de les mestres de pàrvuls, l'autora ens dóna dades força convincents de com s'introdueix una valoració diferent dels nens i les nenes. Els respectius comportaments són descrits de tal manera que, encara que vicis $i$ virtuts semblen repartits, les característiques que s'atribueixen als nens són justament les que la societat valora positivament: agressivitat, franquesa, independència..., mentre que les virtuts de les nenes són banals: ordte, obediència, suavitat. Ara bé, quan ens explica el que va passar en les seves visites a escoles, Belloti introdueix el mateix caràcter menyspreador de les activitats de les nenes. "Així com els nois m'observaren bastant distrets, breument i sense comentaris ni preguntes, com si el fet no els importés gaire, $\mathrm{i}$ van tornar de seguida a les seves activitats, un murmuri va recórrer el grup de noies, una curiositat $\mathrm{i}$ una excitació difícilment contingudes van aparèixer visibles en les mirades immediatament desviades per a no creuar-se amb la meva en els comentaris en veu baixa respecte als meus vestits, el meu aspecte, el que jo feia: igual que porteres repassant el veïnat.» ${ }^{8}$

L'autora constata de fet una diferència de comportament que subtilment es converteix en un judici. $\mathrm{El}$ caràcter fonamental de la diferència, en aquest cas, consisteix que, mentre els nens no presten gaire atenció a

8. E. G. Belloti, Dalla parte delle Bambine, Editions des Femmes, Patís, 1976. 
una visita «perquè no es plantejaven en absolut si m'agradaven o no, ni s'amoinaven a verificar el seu èxit en relació a mi, les segones tendien a abandonar el que feien - amb algunes excepcions, que corresponien precisament a les nenes "diferents", és a dir, molt menys "femenines", més intelligents $i$ autònomes- per a sotmetre's a la meva consideració i a la meva aprovació». Fixem-nos com el text passa d'una descripció a una valoració: el comportament dels nens és superior, denota major independència, el de les nenes denota submissió, actitud negativa en la nostra societat. D'on prové aquesta valoració? En principi, el fet de prestar atenció a una persona desconeguda pot ser considerat de forma superior, igual o inferior a no prestar-n'hi. Pot denotar curiositat, vivesa d'esperit, obertura, sociabilitat, etcètera. Fer què, doncs, és interpretat com a submissió? No pel que denota l'actitud en si, sinó pel grup que l'adopta. Possiblement, si les actituds s'haguessin produit de forma inversa, l'atenció dels nois hauria estat connotada positivament, i la desatenció de les noies fóra considerada com una prova de tancament, desinterès $o$ indiferència.

$\mathrm{Si}$ ens hem estès en aquest exemple és precisament perquè prové d'una feminista avertie, que dedica un llibre al tema de l'educació dels sexes. Llibre que ens demostra que a les nenes se'ls inculquen formes de comportament que les condueixen a ser individus inferiors, a adoptar comportaments de «portera».

Visió, encara, totalment dominada pels valors masculins, que situen els «executius» tan per damunt de les porteres, no ja en termes econòmics, sinó fins i tot de valor humà. Visió que no pot conduir a la superació del problema: si la inferiotitat no ve de prestar atenció, sinó de «ser dona», adoptar unes altres actituds no condueix enlloc. Pot ser útil a una petita minoria capdavantera, però en la mesura que un canvi d'actitud es generalitza, perd, per al conjunt del grup, el caràcter d'avantatge. La prova n'és clara: una dona enginyer rep - no sempre - un salari equivalent al d'un home enginyer. Però quan una professió és exercida per una alta proporció de dones, tendeix a perdre el seu valor econòmic i social, és a dir, es desprestigia.

L'exemple del llibre de la Belloti no constitueix un cas aillat, ans al contrari. Sovint les mestres, i sobretot les que tenen una certa consciència feminista, són molt dures en els seus judicis sobre el comportament de les nenes: les nenes són bledes, beneites. No saben jugar a futbol, ploren fàcilment. Sovint estudien més que els nens, tenen els quaderns més nets i fan millor els deures. Una vegada més, això demostra la seva inferioritat: és una prova de docilitat, de submissió.

Però tampoc la nena no rep una aprovació total quan per fi juga a futbol, $\mathrm{i}$ aprèn l'agressivitat. Si, per atzar, la mestra ho aprova - cosa 
encara poc freqüent- serà la mare qui la trobarà massa «cavallot». És a dir, d'una banda, la nena està sotmesa a un doble sistema de valors, com ja va explicar perfectament Simone de Beauvoir: doble sistema que constantment la desorienta quant a la manera correcta de procedir, al model de comportament que ha de seguir per aconseguir l'aprovació dels adults. De l'altra, l'adopció d'uns models de comportament masculins només representa un cert avantatge quan es tracta de «casos excepcionals». En la mesura que aquesta adopció es generalitza entre les dones, els «motius d'inferioritat» es desplacen: perquè és el fet de ser dona, i no el que concretament es $\mathrm{fa}$, el que comporta una valoració inferior, en termes collectius.

\section{Inseguretat i segregació escolar}

Cal preguntar-se, a partir d'aquí, com aquesta infravaloració del grup femení afecta els seus resultats escolars $i$ constitueix, en els sistemes d'escola mixta, el canal de segregació escolar de la dona.

El tema no ha estat suficientment analitzat, i, per tant, els mecanismes concrets són difícils de precisar. Perquè, certament, no es tracta pas de dir que, en l'avaluació dels alumnes, el professorat té en compte el sexe. $\mathrm{Si}$ en alguns casos pot encara actuar un reflex d'infravaloració dels exàmens o proves de les noies, en general el professorat ha interioritzat la imparcialitat en les avaluacions en què es compta amb elements concrets de judici. La nota és construïda a partir de dades objectives, $i$ la influència de la personalitat de l'alumne, al marge d'aquestes dades, es pot considerar -fins a cert punt- neutralitzada.

Al meu entendre, el mecanisme que provoca la discriminació cal buscar-lo, sobretot, en un tipus d'explicació semblant al que donen Bourdieu i Passeron en relació a la discriminació de classes socials, ${ }^{9}$ és a dir, en les actituds de l'alumne respecte a la cultura, en la seva capacitat l'utilitzar-la «creativament», d'apropiar-se-la com a part de la seva personalitat. La base de l'èxit escolar no és pas saber moltes coses, sinó saber lligar-les entre si, saber manipular-les adequadament, a partir del seu domini. Però l'apro piació de la cultura - com demostraren aquests autors en el cas de les classes socials- és tant més difícil com més diferència hi ha entre els valors internalitzats en l'ambient familiar $i$ social i els valors fonamentals de la cultura acadèmica. D'aquí ve que com més lluny es trobin els valors

9. P. Bourdieu i J. C. Passeron, Les Heritiers, Editions de Minuit, París, 1974. 
familiars $i$ socials inculcats en els primers anys en l'individu dels valors masculins burgesos dominants en el sistema acadèmic, més la cultura acadèmica li és aliena, i més gran és la seva dificultat per apropiar-se-la i saber utilitzar-la en la forma acadèmicament adequada.

Així, el fet que les actituds i els camps d'interès que s'han assenyalat a la noia com a tal formin part del que socialment és considerat com a «no cultura» crea en ella una dualitat: si intenta accedir a la cultura acadèmica adoptant els mateixos esquemes i el mateixos comportaments masculins és considerada «poc femenina» $\mathrm{i}$ rep les sancions socials corresponents. Si accepta el paper social femení, com és encara el cas més frequient, la seva relació amb la cultura es manté com una activitat marginal. La inadequació entre els papers socials que se li imposen i les pautes del món escolar porta a un conflicte, que, a nivell individual, és viscut sota la forma de la inseguretat, la infravaloració de les pròpies possibilitats i la limitació dels objectius acadèmics.

Així, doncs, si partim de la justesa de la cultura acadèmica, ens trobem sempre amb una inferioritat femenina. En la meva experiència de docent a la Universitat $m$ 'ha xocat sempre l'actitud del conjunt de les noies: la seva incapacitat per a fer preguntes a classe i per intervenir en els debats, l'àmbit més restringit de les seves lectures no directament relacionades amb els cursos, la contínua por de no saber-ne, no poder. Actitud que contrasta amb la seva maduresa teal en les converses extraacadèmiques, és a dir, quan es troben en un terreny en el qual no es veuen obligades a adoptar unes pautes en què estan segures que fracassaran.

I el que és més greu, aquest mecanisme d'interiorització de la incapacitat sembla fer-se més i més fort a mesura que desapareixen les traves socials que impedeixen l'accés de les dones a determinats estudis. Mentre es considera que estudiar enginyeria «no és propi d'una dona», l'obstacle se situa a nivell de les normes collectives, i no necessita ser interioritzat. Però quan aquestes normes deixen de ser explícites, l'obstacle prové de la por al fracàs, i és, per tant, en certa manera, més difícil de combatre, perquè ja no es presenta de forma objectiva sinó com una característica individual. Així, per exemple, en el món universitari nord-americà, on hi ha una més alta competivitat entre els estudiants que no pas a Espanya, les declaracions d'impotència de les estudiantes són també molt més freqüents. Mentre la noia espanyola considera que si intenta estudiar enginyeria haurà d'enfrontar-se amb tota mena d'obstacles, a la facultat o fora, o, el que és pitjor, amb unes formes de paternalisme que tendeixen a demostrar-li la seva insignificància, la nord-americana diu: «no sóc prou intelligent», o «no puc competir amb els cervells d'aquest departament». D'aquí ve que la tria d'un tipus d'estudis no es faci generalment, per a la noia, en 
funció de les seves preferències, i per tant del que podria maximitzar les seves capacitats creatives, sinó en funció de la seva inseguretat cultural, i per tant tractant de buscar aquelles disciplines que poden oferir més contactes amb els sistemes de valors que se li han inculcat com a noia, disciplines que generalment coincideixen amb les menys valorades socialment.

La creixent dificultat per a trobar un treball al terme dels estudis complica encara l'elecció de carrera, perquè la competició no és només acadèmica, sinó laboral. Així, per exemple, hi ha una creixent tendència de les noies americanes a estudiar business, fet curiós, perquè, des del punt de vista del sistema de valors implicat i dels papers socials, aquesta és una disciplina diametralment oposada a les «vocacions» femenines. Però aquest és un dels pocs camps laborals en què sembla haver-hi un excés d'oferta de treball en relació a la demanda, i per tant una menor competició. Sistemàticament, les noies declaren que aquests estudis no els interessen, però que és la seva única possibilitat d'un treball relativament ben remunerat. És a dir, adopten l'actitud «passiva» davant la cultura i el mercat de treball, convençudes que les seves capacitats no els permeten de fer una tria en funció dels seus interessos personals.

\section{Què cal canviar}

Si una vegada aconseguida la igualtat escolar formal - cosa que encara no és un fet al nostre país- identifiquem l'obstacle major per a una igualtat dels sexes en l'ensenyament amb l'existència de dos sistemes de valors diferents, seguint uns patrons culturals que mantenen encara una diferència de papers socials per als dos sexes, dues respostes són possibles. Respostes que, encara que d'una manera confusa, han estat formulades pels moviments feministes, únics que fins ara s'han plantejat la qüestió, amb pocs contactes, generalment, amb els moviments pedagògics, molt més centrats en la desigualtat classista i en el caràcter classista de la cultura.

La resposta més òbvia, i també més estesa, parteix del fet que s'educa malament les nenes, se'ls inculquen actituds $i$ valors que les condueixen a la inferioritat cultural. D'aquí se'n dedueix una demanda d'unificació, sobre la base d'una generalització dels sistemes de valors masculins. És a dir, no es qüestiona el model cultural dominant, sinó que del que es tracta és d'eliminar els models culturals dominats, per arribar així a una igualtat de condicions.

Que aquesta posició sigui la més estesa és perfectament comprensible. El caràcter dominant d'un model cultural rau precisament en la 
seva acceptació generalitzada, en la dificultat mateixa de pensar un model cultural a partir d'uns altres punts de vista. Així, per exemple, en els llibres infantils que intenten trobar una via no discriminatòria per a la nena, els canvis fonamentals que s'observen són de dos tipus: la crítica a la posició tradicional de la dona, representada per les actituds de la dona en relació a la família, i l'aparició de nenes que protagonitzen aventures, amb la qual cosa ocupen uns papers tradicionalment atribuits als nens. El mateix patró és utilitzat en la crítica del llenguatge: es feminitzen vocables que fins ara s'utilitzaven només en el gènere masculí, com els noms dels professionals, els termes genèrics, etc.

Aquest model escolar presenta, de fet, una gran coherència amb una determinada fase dels moviments feministes, la fase de crítica de la "mística de la feminitat», de la demanda d'igualtat de drets, de l'èmfasi en la necessitat d'una vida professional «normal» per a la dona. Fase que possiblement representa una etapa necessària en l'abolició de les diferències de rols, i que, lluny de ser sobrepassada, encara no ha estat plenament assumida en la pràctica escolar.

Amb tot, cal preguntar-se per la seva validesa i la seva capacitat per eliminar realment la discriminació sexista, en la mesura que no resol el problema de com integrar en l'ensenyament els valors tradicionalment femenins, que, de fet, continuen subsistint com a part dels valors socials, i per tant probablement internalitzats per la nena.

El segon tipus de resposta posa l'èmfasi en aquest problema, i prové d'aquells sectors del moviment feminista que, més que canviar les nenes, per adaptar-les a un sistema de valors masculins, qüestionen aquest sistema de valors en el seu conjunt. Encara que, en el terreny escolar, no hi ha, de moment, una formulació global ni un model de pràctica que reflecteixin les característiques d'aquest canvi de valors, comencen a aparèixer punts de vista, en textos diversos, que indiquen els trets principals d'aquest tipus d'orientació.

Així, per exemple, la definició que dóna de sexisme una guia nordamericana sobre llibres escolars: «Podem definir el sexisme, en primer lloc, com a opressió i explotació sistemàtica de l'ésser humà sobre la base que pertany al sexe femení. En segon lloc, veiem el sexisme com la repressió de la gent, basada en una definició cultural de la feminitat i de la masculinitat, que impedeix als dos sexes realitzar tot el seu potencial humà.» ${ }^{10}$

10. CIBC Racism and Sexism Ressource Center for Educators, Human and antibuman - Values in Children's books, Council on Interracial Books for Children, Inc., Nova York, 1976. 
Definició extremadament útil, al meu entendre, perquè permet de separar els dos problemes que es deriven del sexisme, els que afecten particularment un grup, les dones, $\mathrm{i}$ els que afecten el conjunt dels individus. La separació entre rols femenins i masculins implica, en primer lloc, l'opressió de les dones; però té una segona conseqüència que és negativa per als dos sexes, malgrat que per a un d'ells sigui menys visible la negativitat, perquè d'ella n'extreu poder. El sexisme, en tant que és l'adopció d'un conjunt de pautes culturals assignades socialment, mutila i frustra homes i dones, perquè els impedeix exterioritzar un conjunt d'impulsos que, originàriament, no es donen separats entre els dos sexes. I en aquest sentit, d'altra banda, la repressió sobre el nen és superior a la que s'exerceix damunt la nena, en la mesura que en aquesta s'estimulen certes actituds de competència, creativitat $\mathrm{i}$ esforç intellectual, mentre que les actituds de donar-se, tendresa, afectivitat, emotivitat, etcètera, són, en els nens, durament sancionades.

En plantejar així el sexisme, la lluita contra la discriminació de la dona en el camp cultural adquireix una nova dimensió, ja que marca uns objectius per al conjunt dels dos sexes, $i$ no pas per a un de sol, encara que les condicions actuals converteixin un d'ells en més sensible a aquest tipus de plantejament. El que s'assenyala és la urgència de fer desaparèixer les diferències entre rols femenins $\mathrm{i}$ masculins, no ja a partir de la generalització del model cultural masculí, sinó d'un nou model cultural que inclogui les pautes anteriorment separades, fet que no implica la «uniformitat» dels comportaments, sinó la capacitat, per a cada individu, independentment del seu sexe, d'adoptar les formes de comportament que li siguin més afins.

És a dir, de cop, les actituds «de portera» deixen de ser menyspreades, junt amb les de la mare de família, les de la nena que plora i les de l'adolescent que aspira a tenir criatures. I es descobreix que aquestes actituds han estat reprimides en el nen, quan, de fet, formen part d'un conjunt de característiques humanes fonamentals $\mathrm{i}$ bàsiques per a l'expressió de la personalitat i per a la convivència. Ja no són les nenes les que han de canviar, perquè, una vegada més, adopten comportaments erronis. És. l'escola la que ha de canviar - $\mathrm{i}$ més enllà el conjunt de valors socials-, i ha d'estimular per igual, en els dos sexes, les característiques abans considerades exclusives. El futbol és per a nens i nenes, però també les nines, o la dansa, o la cuina, si aquestes activitats es consideren importants per a la formació de l'individu.

Així, la fusió dels dos papers culturals dóna un contingut concret al terme coeducació, com a període de transició, a la llarga innecessari en la mesura que es constitueix un model únic integrant els dos anteriors. 


\section{Les dificultats d'un canvi de valors}

Dues dificultats majors apareixen, però, immediatament, en aquest tipus de plantejament. Una d'ordre intern: en què consisteixen, exactament, les pautes culturals femenines a incorporar? L'altra d'ordre extern: com procedir a aquest canvi, en l'actual relació de forces entre els sexes?

La dificultat de definir les pautes culturals femenines de validesa general rau en el fet que implica l'acceptació d'actituds que fins ara han estat totalment desvaloritzades, considerades com a no pertanyents al model de cultura. I els moviments feministes han hagut de començar fent la crítica de la mística de la feminitat, és a dir, negant, en gran part, l'especificitat dels valors històricament considerats femenins, i presentant-los com una degradació dels valors generals. Per tant, tota revalorització d'aquestes actituds pot caure en un intent de reconstruir una mística femenina, que, com a tal, ha tingut unes conseqüències nefastes per al conjunt de les dones, i ha estat un instrument per a mantenir-les en una situació de dominació.

Aquest punt és, de fet, un dels més importants que han de resoldre els moviments feministes, $i$, per ara, una de les més greus fonts de divisió al seu interior: cal fer aparèixer tots els aspectes positius continguts en el sistema de valors històricament femenins, aspectes que, si en la pràctica s'han expressat generalment en una forma alienada - com succeeix amb els valors de tots els grups oprimits- en si mateixos representen una part essencial de les actituds humanes. És així com cal interpretar alguns intents actuals, que, en una lectura superficial, podrien aparèixer com un cant al paper tradicional de la dona: el sentit de la continuitat, del treball exempt de valor de canvi, del lliurament afectiu com a font de creativitat adquireixen, per exemple, en els llibres d'Annie Leclerc ${ }^{11}$ una nova grandesa, que entronca amb una visió humanista paulatinament perduda en els nostres sistemes de valors. Aquesta feina de rescatar de l'anonimat el que han fet les dones és també actualment una de les tasques principals de les feministes nord-americanes, confrontades a una sèrie de contradiccions internes, després de les lluites de finals dels seixanta. Tasca que va des de la reinterpretació del paper de les bruixes, a l'Edat Mitjana, fins a la recollecció de dades de tota mena sobre el paper i les lluites de les dones en la conquesta de l'Oest americà.

Ara bé, l'intent de recuperació d'uns comportaments culturals vàlids no pot ser fet únicament en termes de retorn al passat; és a dir, un canvi

11. Per exemple, a A. Leolerc, Parole de Femme, B. Grasset, París, 1974, i Epousailles, B. Grasset, París, 1976. 
global de valors que integri les actituds històricament femenines només es pot produir si, d'alguna manera, permet de resoldre les contradiccions actuals $\mathrm{i}$ entronca amb un model més general de societat per al futur. Per això la dimensió política dels moviments feministes i la seva necessitat d'aliances, tan discutida, d'altra banda, amb altres moviments socials que aspiren, també, no a canviar la posició relativa d'un grup, sinó a canviar les regles del joc.

Tornant, però, al nivell cultural, un altre perill sorgeix en les feministes que treballen en aquesta tasca de rescat dels valors femenins: el de negar, en aquesta empenta, el valor de la cultura acadèmica transmesa per l'escola, en considerar-ne únicament l'aspecte masculí dominant. L'antiintellectualisme -el menyspreu del cervell, per exemple, com a òrgan «masculi'», en Les Guerrillères - ${ }^{12}$ i la condemna del pensament abstracte, com a forma de coneixement no pròpia de la dona, tenen el seu origen en la necessitat de valoració d'unes formes fins ara menyspreades, però, en termes dels interessos socials globals, $i$ fins $i$ tot de la viabilitat d'un nou model cultural, poden resultar desastrosos. Perquè si, d'una banda, la cultura acadèmica és marcada pels valors d'uns grups socials i per l'absència d'uns altres, també és cert que en ella s'hi recullen els esforços de segles per arribar a la comprensió $i$ al coneixement de la realitat. És a dir, exigir la incorporació d'un altre punt de vista no pot portar a la negació del que ja existeix, perquè tampoc no cal oblidar que el lot de les dones, com a grup dominat, ha estat la ignorància. Reintroduir la dignitat dels valors històricament femenins en la cultura vol dir ampliar-la, obrir-ne les possibilitats, i no restringir-la o implantar noves formes inquisitorials, negant el que han estat instruments bàsics en el desenvolupament dels coneixements. Només en la mesura que els moviments feministes puguin assumir i difondre uns models culturals més amplis que els actuals, que recullin tota la riquesa de les cultures passades $i$ al mateix temps es presentin com una etapa més avançada, en recuperar actituds i valors fins ara oprimits, poden constituir una alternativa real a l'actual sistema cultural.

La qüestió de com procedir a aquest canvi cultural té, encara, una més difícil solució, ja que depèn d'una relació de forces entre els sexes en la qual no es pot dir que la posició de les dones hagi millorat massa. Confinat a l'interès exclusiu de les dones, aquest canvi va per llarg, i totes les propostes que hi apunten adquireixen un caràcter utòpic. Entès com un nou sistema de valors per a una diferent forma de vida collectiva, el caràcter utòpic, com a mínim, disminueix, perquè el conjunt de forces que poden promoure aquest canvi és molt més ampli que els grups feministes.

12. M. Wittig, Las guerrilleras, Seix Bartal, Barcelona, 1974. 
I, en efecte, diversos fenòmens socials, en els últims temps, apunten, des de posicions molt allunyades, a la necessitat d'un canvi cultural en el sentit més amunt descrit. Des del moviment francès del maig del 68 fins als diversos moviments de joves, una sèrie de nous valors apareixen, molt confusament si es vol, que posen en qüestió els valors dominants i redescobreixen aspectes del món tradicionalment femení. I més enllà d'aquests intents esporàdics i per ara no cristallitzats, l'adopció de noves pautes institucionals en països com Suècia demostra la viabilitat d'un canvi en els sistemes de valors, més encara, la seva necessitat i la seva possibilitat, en les societats desenvolupades. Procés lent, que probablement durarà generacions i que no es pot dur a terme si no va acompanyat de canvis polítics i socials més generals. Un estudi realitzat l'any 69 a Uppsala ${ }^{13}$ posa de manifest que, malgrat els canvis produïts a Suècia durant els anys seixanta, en relació al paper dels sexes, els nens i les nenes de cinc, vuit, onze $\mathrm{i}$ quinze anys diferencien fortament aquests papers, en termes de tasques $i$ activitats a realitzar per cada un d'ells. Però les mesures institucionals - com per exemple una política fiscal destinada a afavorir el treball de la dona casada, $i$ les reglamentacions laborals que afavoreixen que l'home s'ocupi també de les criatures petites- poden constituir un element de canvi que, si bé no fa desaparèixer en pocs anys els estereotips de segles, permet almeny de comprendre el seu caràcter convencional i per tant d'enfocar la qüestió del masculí i del femení des d'un nou punt de vista.

13. Citat per C. Safilios-Rothschild, Toward a Sociology of Women, Xerox, Massachusets, 1972. 